\title{
A case of disseminated carcinomatosis of the bone marrow from gastric cancer developing rapidly after a gastrectomy
}

\author{
Shunsuke Sato ${ }^{1}$, Yuji Ishibashi ${ }^{*}{ }^{*}$, Koichiro Kawasaki ${ }^{1}$, Ryoto Yamazaki ${ }^{2}$, Fumihiko Hatao ${ }^{1}$, Yasuhiro Morita ${ }^{1}$
} and Kazuhiro Imamura'

\begin{abstract}
Background: Disseminated carcinomatosis of the bone marrow (DCBM) is often associated with disseminated intravascular coagulation (DIC) and a poor prognosis. Moreover, the timing of the diagnosis varies. We presented herein the first report of a case of DCBM from gastric cancer that developed rapidly after a gastrectomy.

Case presentation: A 42-year-old male patient was referred to us for gastric cancer. Preoperative laboratory tests were normal. Abdominal computed tomography (CT) revealed no obvious bone metastasis, and he underwent a laparoscopic distal gastrectomy. On postoperative day (POD) 1, laboratory data indicated severe thrombocytopenia. Postoperative bleeding requiring reoperation was found. Afterwards, he complained of lower back pain. His ALP and LDH gradually became elevated. On POD 8, DIC was diagnosed. CT and bone scintigraphy showed multiple, widespread bone metastases. Based on these findings, DCBM from gastric cancer was diagnosed. Systemic chemotherapy was started on POD 12. The DIC subsided during the first course, and he was discharged on POD 21. The patient died of tumor progression 7 months later.
\end{abstract}

Conclusion: When thrombocytopenia is observed immediately after a gastrectomy for gastric cancer, the possibility of DCBM should be considered.

Keywords: Bone marrow metastasis, Disseminated carcinomatosis of the bone marrow, Gastrectomy, Gastric cancer

\section{Introduction}

Bone metastasis diffusely invading the bone marrow with attendant hematological disorders is called disseminated carcinomatosis of the bone marrow (DCBM). DCBM is often associated with disseminated intravascular coagulation (DIC) and a poor prognosis [1]. The timing of diagnosis of the bone and bone marrow metastases varies, and the median interval from the diagnosis of gastric cancer to the detection of a bone marrow metastasis was previously reported as 161 days [2]. Herein, we reported

\footnotetext{
*Correspondence: ishibashi_y@live.jp

1 Department of Surgery, Tokyo Metropolitan Tama Medical Center, 2-8-29

Musashidai, Fuchu, Tokyo 183-8524, Japan

Full list of author information is available at the end of the article
}

the first case of DCBM associated with gastric cancer that developed rapidly after a gastrectomy.

\section{Case report}

A 42-year-old male patient was referred to our department for gastric cancer. He was asymptomatic on admission. A laboratory test on preoperative day 13 showed elevated carbohydrate antigen (CA) 19-9. Other laboratory values, including platelet count (PLT), alkaline phosphatase (ALP), and lactate dehydrogenase (LDH), were normal (Table 1). Upper gastrointestinal endoscopy showed a type 3 lesion on the lesser curvature of the gastric angle. Pathological analysis of a biopsy specimen demonstrated a poorly differentiated adenocarcinoma. Abdominal computed tomography (CT) performed at the previous hospital on preoperative day 20 revealed 
Table 1 Preoperative and postoperative laboratory data

\begin{tabular}{|c|c|c|c|c|}
\hline & Preoperative & POD 1 & POD 8 & POD 19 \\
\hline WBC $(/ \mu \mathrm{l})$ & 7500 & 10,000 & 14,800 & 4400 \\
\hline $\mathrm{RBC}\left(\times 10^{4} / \mu \mathrm{l}\right)$ & 532 & 411 & 337 & 306 \\
\hline $\mathrm{Hb}(\mathrm{g} / \mathrm{dl})$ & 15 & 11.7 & 9.7 & 9.0 \\
\hline $\mathrm{Ht}(\%)$ & 43.9 & 34.3 & 28.9 & 26.7 \\
\hline $\operatorname{PLT}\left(\times 10^{4} / \mu \mathrm{l}\right)$ & 17 & 4.6 & 6.3 & 24.8 \\
\hline PT (\%) & 84.1 & - & 38.6 & 74.7 \\
\hline APTT (s) & 27.3 & - & 33.9 & 23.4 \\
\hline $\mathrm{Fib}(\mathrm{mg} / \mathrm{dl})$ & 289 & - & 171 & \\
\hline $\mathrm{FDP}(\mu \mathrm{g} / \mathrm{ml})$ & - & - & 296 & 85.4 \\
\hline D-Dimer $(\mu \mathrm{g} / \mathrm{ml})$ & - & - & 150 & 34.2 \\
\hline TP $(g / d l)$ & 7.2 & - & 6.3 & 5.8 \\
\hline Alb (g/dl) & 4.1 & 3.1 & 3.2 & 3.4 \\
\hline T-Bil (mg/dl) & 0.8 & 1 & 1.2 & 0.6 \\
\hline AST (U/I) & 16 & 232 & 44 & 19 \\
\hline $\operatorname{ALT}(\mathrm{U} / \mathrm{I})$ & 13 & 288 & 60 & 20 \\
\hline LDH (U/I) & 184 & - & 945 & 410 \\
\hline $\mathrm{ALP}(\mathrm{U} / \mathrm{I})$ & 218 & 342 & 1055 & 1048 \\
\hline BUN (mg/dl) & 11.1 & 20.5 & 11.5 & 14.8 \\
\hline $\mathrm{Cr}(\mathrm{mg} / \mathrm{dl})$ & 0.7 & 1.13 & 0.62 & 0.63 \\
\hline CRP $(\mathrm{mg} / \mathrm{dL})$ & 2.04 & 7.04 & 7.51 & 0.33 \\
\hline CEA (ng/ml) & 2.9 & - & - & - \\
\hline CA19-9 (U/ml) & 216.4 & - & - & - \\
\hline
\end{tabular}

$P O D$ postoperative day

wall thickening with enhancement of the gastric angle and some regional lymph node swelling. Bone metastasis was not diagnosed (Fig. 1). Based on these findings, clinical stage III gastric cancer (cT3N+M0) was diagnosed based on the Japanese Gastric Cancer Association Classification, 14th Edition [3]. The patient underwent a laparoscopic distal gastrectomy and D2 lymph node dissection. The total duration of the surgery was $305 \mathrm{~min}$, and the blood loss was $120 \mathrm{ml}$. No bleeding disorder was found during surgery and no intraoperative blood transfusion was required. On postoperative day (POD) 1, the drainage showed evidence of hemorrhage. Laboratory data indicated severe thrombocytopenia $\left(4.6 \times 10^{4} / \mu \mathrm{l}\right)$. Continuous bleeding requiring reoperation was found. Exploratory laparoscopy was performed. The intraoperative findings demonstrated hematomas around the greater omentum, and the points of bleeding were some stumps of the omentum. Lavage and hemostasis were performed under laparoscopy. After reoperation, the bleeding did not recur, but the patient complained of lower back pain. His PLT remained low while his ALP and LDH gradually became elevated (Fig. 2). Findings on POD 8 showed PLT $6.3 \times 10^{4} / \mu \mathrm{l}$, ALP $1055 \mathrm{U} / \mathrm{l}$ (ALP1: 23\%, ALP2 + 3: 77\%), LDH 945 U/l, D-dimer $150 \mu \mathrm{g} /$ $\mathrm{ml}$, and FDP $296 \mu \mathrm{g} / \mathrm{ml}$ (Table 1). Based on these findings, DIC was diagnosed. CT showed multiple, widespread, low-density masses in the vertebrae which were not detected on preoperative $\mathrm{CT}$, and bone scintigraphy revealed multiple hot spots throughout most of the spine, pelvis, and ribs (Figs. 3, 4). Although a bone biopsy was not able to be performed because of the patient's poor condition, DCBM from gastric cancer was clinically diagnosed. The histopathological examination revealed the following: L, Less, Type3, $51 \times 27 \mathrm{~mm}$, por2 $>$ tub2, pT3(SS), INFc, Ly1c, V1a, pPM0, pDM0, pN3b (42/53). Human epidermal growth factor receptor 2 was negative. The final diagnosis was T3N3bM1 Stage IV.

Systemic chemotherapy with S-1+cisplatin (SP) was started on POD 12. The DIC subsided during the first course, and the patient was discharged on POD 21 (Table 1, Fig. 2). Radiation 30 Gy in ten fractions for the bone metastases was started on POD 24. After two cycles of SP, the CA19-9 levels rose again. Thereafter, he received two courses of paclitaxel and ramucirumab as the second-line treatment, two courses of nivolumab as the third line treatment, and one course of CPT-11 as the fourth line treatment. However, these regimens did not achieve a curative effect. The patient died seven months postoperatively.

\section{Discussion}

Gastric cancer most commonly spreads to the peritoneum, liver or lungs. The incidence of bone metastasis is $2-3 \%[4,5]$. A bone marrow metastasis is rare, with an incidence of less than 1\% [6]. In DCBM, cancer cells diffusely infiltrate the bone marrow, then proliferate explosively, causing bone destruction and hematological complications [1]. Elevated expression of receptor activator of nuclear factor kappa-B ligand in the gastric tissues plays an important role in DCBM pathogenesis [1]. The majority of DCBM patients are of younger age with histologically poorly differentiated adenocarcinoma or signet ring cell carcinoma, elevated ALP and LDH, thrombocytopenia, anemia, and extensive bone metastases [2]. The patient in the present case had gastric cancer with several, typical features of DCBM, such as poorly differentiated adenocarcinoma, thrombocytopenia, elevated serum ALP and LDH, widespread bone metastasis, and DIC, based on which DCBM from gastric cancer was clinically diagnosed.

The prognosis of DCBM is extremely poor. Park et al. reported that patients with a bone marrow metastasis had significantly poor survival compared to those without a bone marrow metastasis [5]. Kim et al. reported that the median survival time of patients with both bone 

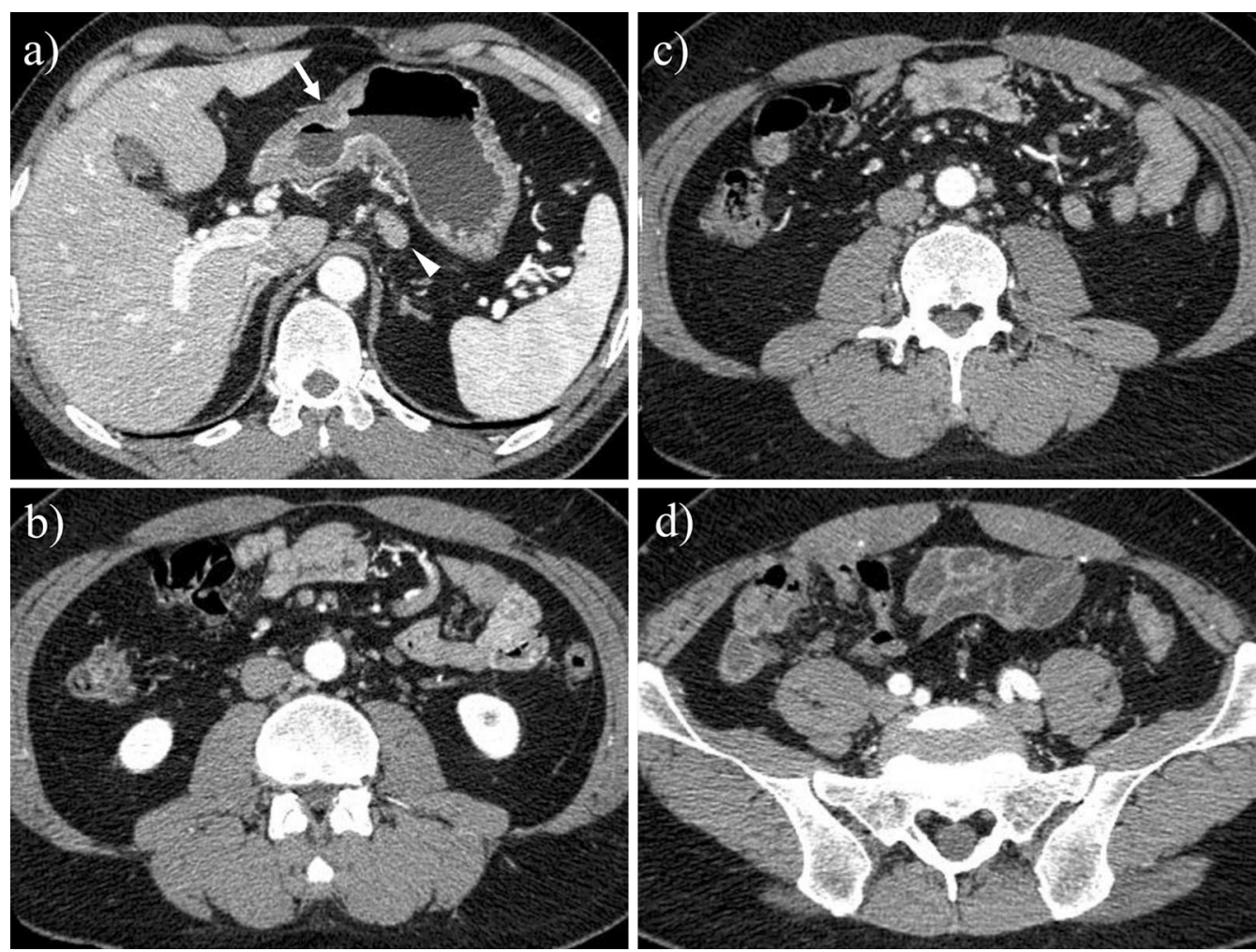

Fig. 1 Preoperative CT. a CT revealed wall thickening with enhancement of the gastric angle (arrow) and regional lymph node swelling (arrowhead). b-d No obvious bone metastasis was observed

and bone marrow metastases was 4.0 months while that of patients with only a bone metastasis was 8.7 months [2]. The present patient died only seven months after surgery despite intensive chemotherapy.

The timing of the diagnosis of bone and bone marrow metastases varies. Turkoz et al. reported that the median duration from the diagnosis of gastric cancer to the detection of a bone metastasis was 14.2 months in resected gastric cancer patients and 8.2 months (range 2.5-121.1 months) in inoperable gastric cancer patients [4]. On the other hand, Kim et al. reported that the median interval from the diagnosis of gastric cancer to the detection of a bone marrow metastasis was 161 days (range 0-2860 days) [2]. The present patient was asymptomatic, his serum PLT, ALP, and LDH levels were normal, bone metastasis was not diagnosed by preoperative $\mathrm{CT}$, and no bleeding disorder was found during laparoscopic gastrectomy. Immediately after the gastrectomy, thrombocytopenia suddenly developed; a hemorrhage requiring reoperation was found, and the ALP and LDH became elevated. CT and bone scintigraphy showed multiple bone metastases, leading to the diagnosis of DCBM which developed rapidly after the gastrectomy. No similar cases have been reported previously. Although in the present case, the accurate cause and mechanism by which the bone metastasis and DCBM progressed rapidly almost immediately after surgery were unclear, it is possible that a subclinical bone micrometastasis escaped detection on CT before his first operation and operative invasiveness and the stress induced by the gastrectomy may have contributed to the rapid and diffuse progression of bone metastasis, causing the cancer cells to infiltrate the bone marrow where they proliferated explosively and developed into DCBM. Furthermore, it is possible that reoperation for the postoperative bleeding increased the surgery-induced stress in this patient. The body's response to surgery-induced stress has direct effects on tumor cells or can alter the tumor microenvironment, increasing the risk of recurrence [7]. Also, surgery can lead to the activation of early and key components of the innate and adaptative immune systems, and platelet activation, neutrophil extracellular traps, and immunosuppression are significant factors in promoting tumor growth and metastasis [8]. 

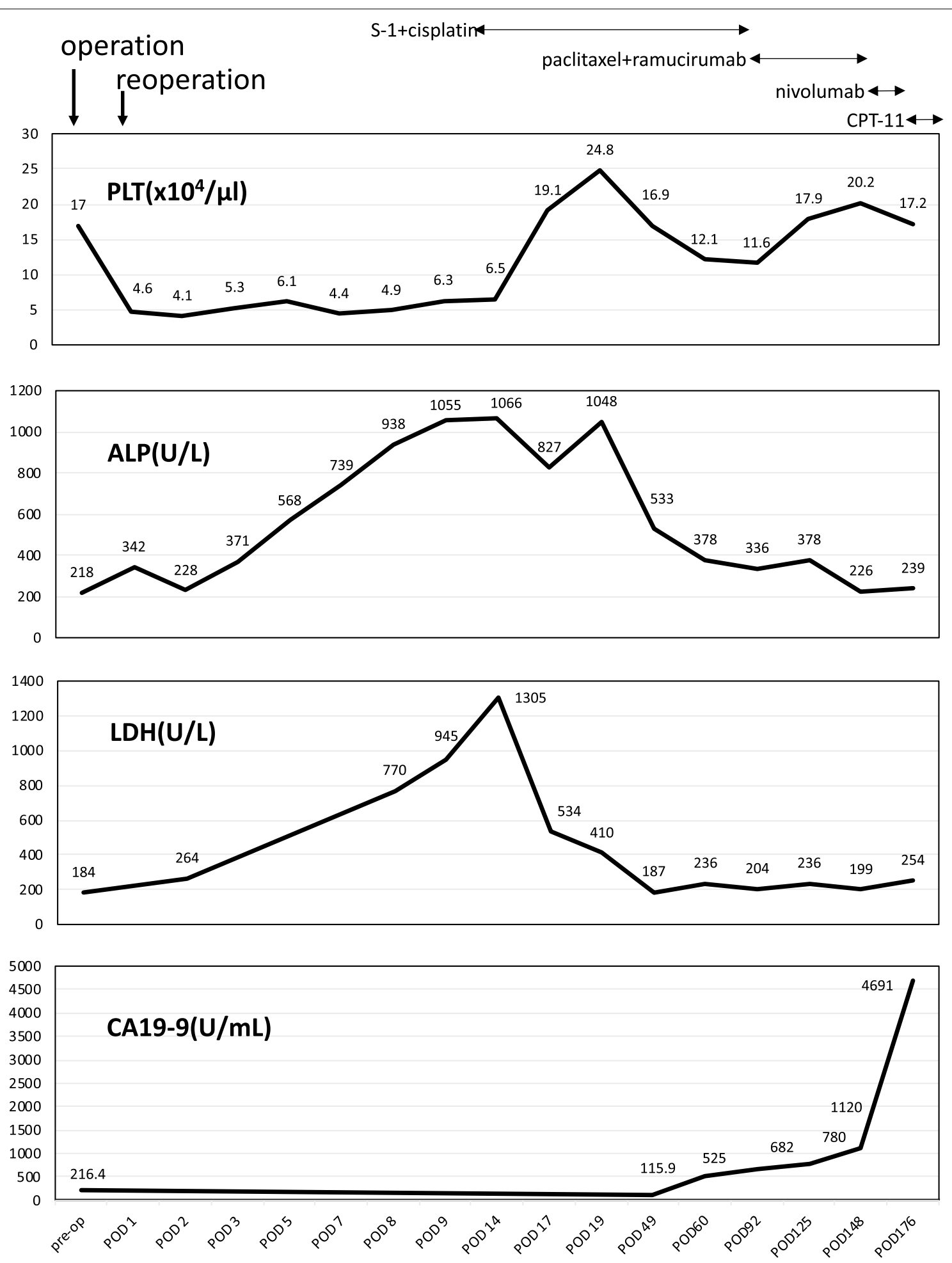

Fig. 2 Clinical course of the patient including the surgery, chemotherapy, and clinical data

\section{Conclusion}

We reported the first case of DCBM associated with gastric cancer that developed rapidly after a gastrectomy. The possibility of DCBM should be considered in cases of thrombocytopenia occurring immediately after a gastrectomy for advanced gastric cancer. 

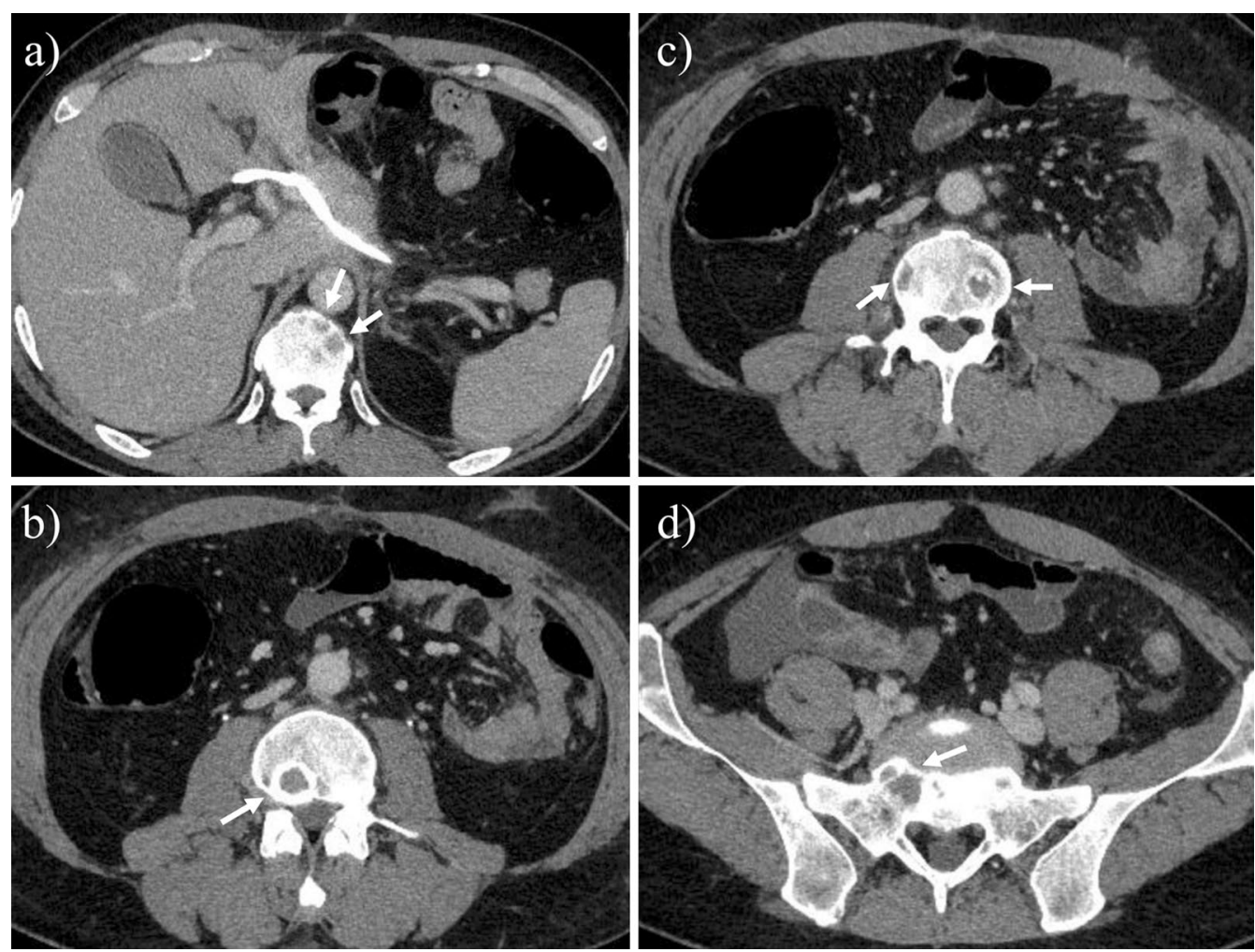

Fig. 3 Postoperative CT. Multiple, widespread, low-density masses were seen in the vertebrae (arrow)

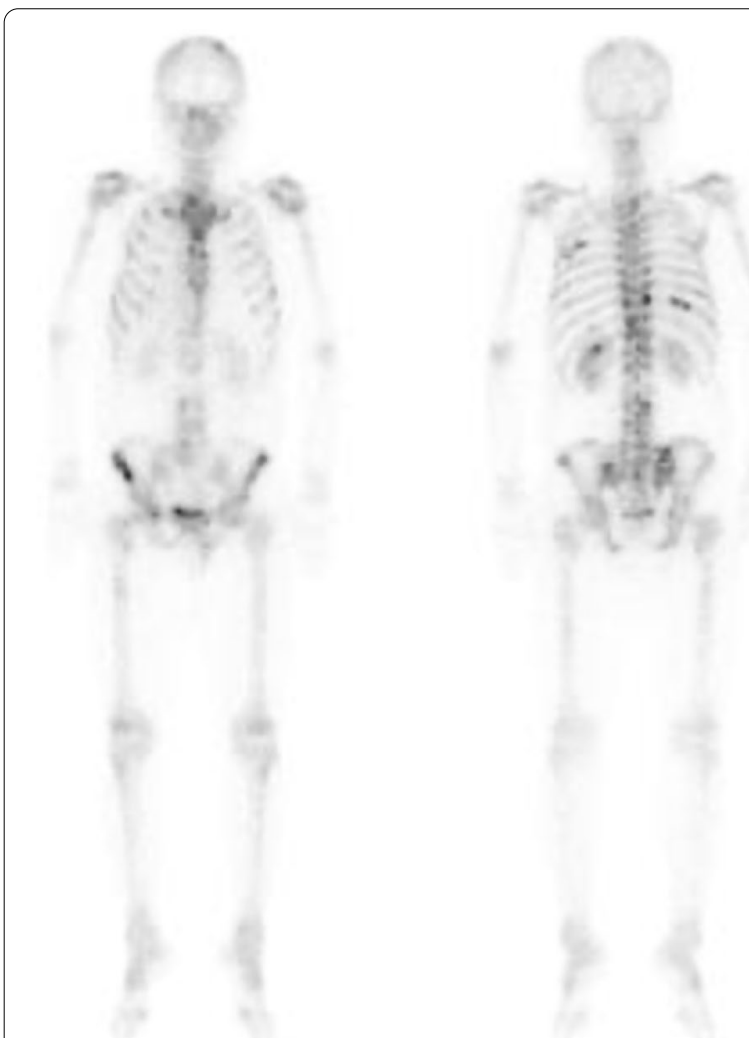

Fig. 4 Bone scintigraphy revealed multiple hot spots throughout most of the spine, pelvis, and ribs

\section{Abbreviations}

DCBM: Disseminated carcinomatosis of the bone marrow; DIC: Disseminated intravascular coagulation; CA 19-9: Cardioantigen 19-9; PLT: Platelet count; ALP: Alkaline phosphatase; LDH: Lactate dehydrogenase; CT: Computed tomography; POD: Postoperative day; SP: S-1 + cisplatin.

\section{Acknowledgements}

None.

\section{Authors' contributions}

$\mathrm{KI}$ performed the surgery. SS and $\mathrm{YI}$ carried out data acquisition and drafted the manuscript. KK, RY, FH, YM, and KI revised the manuscript. All the authors have read and approved the final version of the manuscript.

\section{Funding}

None.

\section{Availability of data and materials}

Data in the study are not available to the public due to concerns about patient privacy but may be obtained from the corresponding author on reasonable request.

\section{Ethics approval and consent to participate}

The present study was conducted in accordance with the ethical standards of our institution

\section{Consent for publication}

Written informed consent was obtained from the patient for the publication of the details of this case and any accompanying images.

\section{Competing interests}

The authors declare that they have no competing interests. 


\section{Author details}

${ }^{1}$ Department of Surgery, Tokyo Metropolitan Tama Medical Center, 2-8-29 Musashidai, Fuchu, Tokyo 183-8524, Japan. ${ }^{2}$ Department of Surgery, Tokyo Metropolitan Matsuzawa Hospital, 2-1-1 Kamikitazawa, Setagaya City, Tokyo 156-0057, Japan

Received: 9 December 2020 Accepted: 8 February 2021

Published online: 16 February 2021

\section{References}

1. Kusumoto $\mathrm{H}$, Haraguchi M, Nozuka Y, Oda Y, Tsuneyoshi M, Iguchi $\mathrm{H}$. Characteristic features of disseminated carcinomatosis of the bone marrow due to gastric cancer: the pathogenesis of bone destruction. Oncol Rep. 2006;16:735-40.

2. Kim HS, Yi SY, Jun HJ, Lee J, Park JO, Park YS, et al. Clinical outcome of gastric cancer patients with bone marrow metastases. Oncology. 2007;73:192-7.

3. Sano T, Kodera Y. Japanese classification of gastric carcinoma: 3rd English edition. Gastric Cancer. 2011:14:101-12.
4. Turkoz FP, Solak M, Kilickap S, Ulas A, Esbah O, Oksuzoglu B, et al. Bone metastasis from gastric cancer: The incidence, clinicopathological features, and influence on survival. J Gastric Cancer. 2014;14:164-72.

5. Park HS, Rha SY, Kim HS, Hyung WJ, Park JS, Chung HC, et al. A prognostic model to predict clinical outcome in gastric cancer patients with bone metastasis. Oncology. 2011;80:142-50.

6. Ergun Y, Uncu D, Yazici O, Ucar G, Karabuga EK, Zengin N. Gastric cancer patients with bone marrow metastasis: a single-center experience and review of the literature. Eurasian J Med Oncol. 2017:1:160-3.

7. Chen Z, Zhang P, Xu Y, Yan J, Liu Z, Lau WB, et al. Surgical stress and cancer progression: twisted tango. Mol Cancer. 2019;18:132

8. Onuma AE, Zhang H, Gil L, Huang H, Tsung A. Surgical stress promotes tumor progression: a focus on the impact of the immune response. J Clin Med. 2020:9:4096.

\section{Publisher's Note}

Springer Nature remains neutral with regard to jurisdictional claims in published maps and institutional affiliations.

\section{Submit your manuscript to a SpringerOpen ${ }^{\circ}$ journal and benefit from:}

- Convenient online submission

- Rigorous peer review

- Open access: articles freely available online

- High visibility within the field

- Retaining the copyright to your article

Submit your next manuscript at $\boldsymbol{\nabla}$ springeropen.com 